\title{
Covid-19 and Animals: A Review
}

\author{
A. Indhu Prathibha*, V. Bhanu Rekha and V. J. Ajay Kumar \\ Department of Veterinary Public Health and Epidemiology, River Rajiv Gandhi Institute of \\ Veterinary Education and Research, Puducherry, India \\ *Corresponding author
}

Coronavirus disease 2019 (COVID-19) caused by severe acute respiratory syndrome coronavirus 2 (SARS-CoV-2) was first reported in China and rapidly spread worldwide. WHO declared this as a pandemic on March 11, 2020. This new virus belongs to the same family of viruses as SARS-CoV associated with civet cats, and MERS-CoV associated with dromedary camels.SARS-CoV-2 is known to infect pet animals, domestic and wild animals in addition to humans. Bats are shown to be the reservoir host and snakes as well as pangolins are suggested to be the intermediate hosts of this virus. Pet dogs and cats have tested positive in various countries. In addition to these animals, lions, tigers, ferrets and minks were also infected. Although it is still not certain that humans can transmit COVID-19 to their pets or other animals, whether mutated SARS-CoV-2 can affect animals, it is recommended to follow some preventive measures and basic animal hygiene. There is no literature proving the transmission of the virus from the infected pets to their owners. However, social distancing needs to be maintained with animals as with humans. By doing so, we can reduce the human as well as zoonotic transmission of SARS-CoV-2.

\section{Introduction}

Coronaviruses $(\mathrm{CoVs})$ are a group of viruses that belong to the subfamily Orthocoronavirinae in the family Coronaviridae, Order Nidovirales. The first isolation of coronavirus took place in 1937 from birds infected with the infectious bronchitis virus, which is capable of devastating poultry stock. It started with the first report of a new type of upper-respiratory tract disease among chickens in North Dakota, US, in 1931. The causative agent was identified as a virus in 1933. By 1936, the disease and the virus were recognised as unique from other viral disease. They became known as infectious bronchitis virus (IBV), but later officially renamed as Avian coronavirus. In 1961 a new virus was isolated from a boy in Epsom England with the 
symptoms of common cold. Almost similar viruses were isolated from medical students of university of Chicago in 1966. Based on comparison of two viruses, in 1967, June Almeida and David Tyrrell invented the collective name coronavirus, as all those viruses were characterised by solar coronalike projections (called spikes) on their surfaces (Tyrell and Felder, 2002). Coronaviruses have also been discovered from pigs, dogs, cats, rodents, cows, horses, camels, Beluga whales, birds and bats. As of 2020, about 39 species are described. Bats are found to be the richest source of different species of coronaviruses. All coronaviruses originated from a common ancestor about 293 million years ago. Zoonotic species such as Severe acute respiratory syndrome are related coronavirus (SARS-CoV), Middle East respiratory syndrome-related coronavirus (MERS-CoV) and Severe acute respiratory syndrome-related coronavirus 2 (SARS-CoV2), the aetiological agent of the COVID-19 pandemic. Coronaviruses are the cause of about 15-30\% of common colds (Syed, 2020).

In December 2019, China alerted the World Health Organization to a cluster of unusual cases of pneumonia that were diagnosed in Wuhan, in Hubei province, China. Although the cause at that time was unknown, the patients' symptoms and clinical features were most suggestive of a viral etiology. Subsequently, after a month of the first report of infection on December 12, 2019, the causative agent was swiftly identified as a member of Coronaviridae family, and on January 12, 2020, the World Health Organization (WHO) designated this fastspreading virus as "2019-novel coronavirus (2019-nCoV)", and Novel Coronaviral Pneumonia and $\mathrm{CoV}$-associated diseases were referred to as "COVID-19" by WHO on February 11, 2020 (Du et al., 2020; Gralinski and Menachery, 2020). Later, this emerging virus was designated as "SARSCoV-2" by the
Coronavirus Study Group (CSG) of the International Committee on Taxonomy of Viruses (ICTV) (Gorbalenya et al., 2020). On March 11, 2020 the WHO declared the situation as a pandemic which is threatening mankind to a great extent (Phadke and Saunik, 2020; Zheng, 2020).

CoVs are known to circulate in mammals and birds (Abdel-moneim and Abdelwhab, 2020). According to previous studies, both SARS-CoV and MERS-CoV are zoonotic in origin, originally coming from bats, with SARS-CoV spreading from bats to palm civets and/or to humans, and MERS-CoV spreading from bats to dromedary camels, and humans (Li et al., 2020).

\section{Causative Agent, Reservoirs and Host}

CoVs are a subfamily of a single-strand RNA, large and enveloped viruses. They are classified into four genera based on their genetic properties, namely Alphacoronavirus $(\alpha-\mathrm{CoV}), \quad$ Betacoronavirus $\quad(\beta-\mathrm{CoV})$, Gammacoronavirus $\quad(\gamma-\mathrm{CoV}), \quad$ and Deltacoronavirus ( $\delta$-CoV) (Lau et al., 2015). Both $\alpha$ - and $\beta-\mathrm{CoV}$ genera are known to infect mammals, whilst $\delta$ - and $\gamma$-CoVs infect birds (Li et al., 2019). The first identification of human coronaviruses ( $\mathrm{HCoV})$ occurred in the 1960s, as it was identified in the nostrils of patients with the common cold. There are two human coronaviruses, OC43 and 229E, which are responsible for a large proportion of common colds. All discovered coronaviruses that are causing illness for humans were originating from animals. Generally, these animals were either rodents or bats (Fan et al., 2019).

By the 10th of January 2020, the SARS-CoV2 genomic sequence was detected for the first time; it appeared as new identified form of beta-CoV, and the genetic identity between the sequenced samples obtained from the 
origin of the outbreak in Wuhan matches by more than $99.98 \%$. Genetically, SARS-CoV-2 was reported to be more similar to SARS-CoV than MERS-CoV (Lu et al., 2020). According to the phylogenetic analysis, the RBD of SARS-CoV-2 appears to be a mutated strain of its most closely related bat virus, RaTG13 (Rhinolophus affinis) (Anderson et al., 2020). Due to this close relation, the SARS-CoV-2 was believed to infect people from bats after mutation.

Bats were the source of both SARS-CoV and MERS-CoV that infect humans by civet cats and camels, respectively. Besides, bats were the natural hosts of SARS-CoV-2 as per the phylogenic studies of SARS-CoV-2 comparing with other $\mathrm{CoVs}$, which showed that the novel virus is $96 \%$ identical to two SARS-like CoVs isolated from bats called batSL-CoVZX45 and bat- SLCoVZX21(Lu et al., 2020). Ji et al., (2020) suggested that snakes act as an intermediate host to the virus where homologous recombination within the $\mathrm{S}$ protein had occurred, transferring the virus from bats to humans. Another study in Guangzhou, China proposed that the anteating, long-snouted pangolins are the prospect intermediate host of SARS-CoV-2 depending on a $99 \%$ match in genetic identity between $\mathrm{CoV}$ discovered in pangolins and SARSCoV- 2 (Xiao et al., 2020).

\section{Zoonotic origin of sars-cov-2}

SARSCoV emerged in humans that had contact with palm civets in China in 2002 and resulted in a global SARS epidemic that lasted 8 months and took 774 lives (Totura and Bavari, 2019). Ten years later, in 2012, MERS-CoV appeared in humans that had close contact with dromedary camels in Saudi Arabia where it remains a major public health concern, spread to 27 countries claiming 858 lives (Totura and Bavari, 2019). Similarly for SARS-CoV-2, due to evidence of several infected people's exposure to seafood in the wet animal market in Wuhan City, it is assumed that the virus was likely originated from animals and transmitted to humans, then maintains human-to-human transmission (Ji et al., 2020; Rothan and Byrareddy, 2020). It is now suggested that bats are the initial reservoir of the virus (Temmam et al., 2020).

A group of researchers from the Agricultural university of South China analyzed over one thousand metagenomic samples and observed that about $70 \%$ pangolins out of more than 1000 metagenomic samples were found to be positive for the coronavirus (Lu et al., 2020). Also, there was $99 \%$ similarity of the genetic sequence between the pangolins and the present infectious human strain (Zhang and Holmes, 2020). Based on these evidence, there is a high probability of the pangolins to be one of the intermediate host of COVID-19 (Lam et al., 2020).

\section{Animals and Covid-19}

\section{Role of domestic animals}

On January 29, 2020, a member of the senior expert team from China's National Health Commission stated on Chinese state television that pet owners should take extra care of their animals because (1) the virus "moves between mammals"; (2) if your animals "come into contact with the outbreak or people infected with the virus, then your pets should be put in quarantine"; and (3) "because the epidemic spreads between mammals, therefore we should take precaution against other mammals" (Safoora, 2020). This prompted the World Health Organization to state that "there is no evidence dogs and cats can be infected with the virus"' (Williams, 2020). The Ministry of Health in Singapore released a statement discussing the theoretical possibility that COVID-19 could spread from animals to humans or vice versa but that they did not see 
pets as a "serious vector of transmission" and that there were "no plans to isolate, do contact tracing for pets, or exercise any form of quarantine for animals"' (Mahmud, 2020). On March 13, WHO stated that "pets are generally safe from being infected with coronavirus"' (Zhou, 2020). But they later admitted "that pets can get infected, but there is no evidence pets can spread the disease or that the disease can cause an animal to fall ill', (Zhou, 2020).

\section{Pomeranian dog}

On February 26,2020, Hong Kong's Agriculture, Fisheries, and Conservation Department announced that the nasal and oral cavity samples of a 17 year old pet dog of a COVID-19 patient had tested "weak positive" through RT-PCR. The dog did not show any symptoms of illness. However, the results of the fecal sample and the rectal swab were negative. The reports of RT-PCR testing on the nasal cavity repeated on February 28, March 2, 5, and 9 were again found to be weak positive, indicating the presence of a minute amount of SARS-CoV-2 RNA in these samples. Moreover, the results of the genome data sequencing of the dog and its close human contacts completed on March 12 suggested a high similarity between the viral sequences. The virus neutralizing antibody test completed on March 12 was negative. The RT-PCR conducted on March 12 and 13 consecutively were reported to be negative and thus the Pomeranian was released on the following day. However, the dog died three days later and unfortunately the owner of the dog did not allow a postmortem examination (Mallapaty, 2020).The fact that the dog was asymptomatic along with the inability to recover live virus led to this finding being attributed to environmental contamination from the owner (Simin et al., 2020). However, on March 9, ProMED-mail posted the remarks of the associate director for the Joint Institute for Virology at Hong Kong University who stated "the dog's lack of symptoms showed the virus could live inside it, allowing the animal to secrete and spread the virus at the same time"' (Simin et al., 2020).

\section{German Shepherd dog}

On March 19, 2020, a two year old German shepherd dog living in Pok Fu Lam was tested positive for COVID-19. As seen earlier, the 30 years old owner of the dog was also infected with the virus. However, the dog did not show any symptoms of respiratory discomfort during its quarantine period (Sit et al., 2020). The Agriculture, Fisheries and Conservation Department reported that the results of RTPCR on the oral and nasal samples of the dog came out to be positive.

\section{Cat in Belgium}

On March 27, 2020, the first positive cat was diagnosed with COVID-19 in Belgium (Brown 2020, Bryner 2020). The reports of PCR (high throughput sequencing) detected the viral RNA of SARS-CoV-2 in the faeces and vomit of the cat. The cat was likely to pick up the virus from its owner who after travelling to northern Italy fell sick with SARS-CoV- 2.Contrary to the earlier assertions by health agencies that the virus could not cause illness in pets, the cat developed both respiratory and enteric symptoms.

The cat was quarantined and took 9 days to recover. The Scientific Committee in Belgium said it was "unable to assess the risk" of animal-to-human transmission but did not recommend testing pets until validated diagnostics were available (AFSCA, 2020). Between March 27 and 30, scientists still said they considered pets to be "dead end hosts" (Stone, 2020) and that "the risk of animal to human transmission is very small" and that 
"'animals are not vectors of the epidemic, so there is no reason to abandon your animal", while advising owners "not to rub their nose against their pets"' (Brown, 2020).

\section{Cat in Hong Kong}

A pet cat in Hong Kong was tested positive with COVID- 19 on March 31, 2020 after it was quarantined on March 30 after its owner, a women of the Shek PaiWan Estate, Aberdeen was infected with the virus. The samples collected from the nose, mouth, and rectum of the cat tested positive for the virus. However, the cat did not show any signs of the disease (Pet cat in Hong Kong 2020).

\section{Studies on cats}

Chinese researchers studied 100 stray and house cats from Wuhan, China, for the presence of SARS-CoV-2-specific antibodies and found $15 \%$ of them had antibodies in their blood that were specific to the novel coronavirus. On April 18, two cats reportedly tested positive for SARS-CoV-2 in New York. Both cats had owners who were COVID-19 positive, and both animals were exhibiting respiratory signs (Zhang, 2020). On April 1, Chinese authors posted several preprint non peer-reviewed publications on transmission studies in animals (Shi et al., 2020) and a serological study in cats (Zhang et al., 2020).

These studies are the first experimental studies in animals and provide valuable insights into SARS-CoV-2 infection in a variety of species. The transmission study showed that the virus replicates efficiently in cats, that it causes severe disease in juvenile cats, and that there is droplet transmission of the virus from infected to naive cats. One scientist stated that she doubts the results of the transmission study because they infected cats with very high doses of virus and they do not replicate in nature (Zhen, 2020).

\section{Role of domestic animals}

Domestic animals such as ferrets were also reported to be highly susceptible to SARSCoV-2 (shi et al., 2020). A recent experimental study verified that infected ferrets can transmit SARS-CoV-2 efficiently to other naive ferrets via direct contact and air (Richard et al., 2020). In contrast, other domestic animals like pigs and poultry are not susceptible to SARS-CoV-2 (Shi et al., 2020; Schlottau et al., 2020) while there is no evidence so far on the susceptibility of livestock animals like camel, horse, sheep, cow and donkey.

\section{Minks in Netherlands}

Minks, which are farmed for their fur, are also susceptible to SARS-CoV-2 with the ability to transmit the virus among each other. The first positive mink case was reported from the Netherlands on 23 and 25 April 2020, where there are around 125 mink farms. Some of these minks displayed signs of respiratory signs (mostly nasal discharge). Histological findings revealed severe diffuse pneumonia with hyperaemia, alveolar damage as well as air containing alveolar lumina in lungs of the dead minks. The qPCR analysis detected the presence of viral RNA in the liver and intestines of some animals. Also, the throat swabs of all the necropsied animals showed the presence of viral RNA. On further investigation of the farm owners and workers, four members on one of the two farms have had respiratory disease symptoms in the start of April but did not get checked for SARSCoV-2 infection. Additionally, one of the people who stayed in the farm was later detected with SARS-CoV-2 by the end of April. Moreover, one of the workers of farm two was hospitalized on March 31 due to COVID-19. Therefore, it is assumed that human-to-animal transmission was the most likely scenario for the infection of the minks 
(Oreshkova et al., 2020). Since the abovementioned first reported case, other countries like Denmark (Promed-Mail, 2020) and Spain (OIE, 2020) have also reported similar COVID-19 cases in this animal.

\section{Role of wild animals}

Concerning other wild animals, tiger and lion were confirmed to be susceptible to SARSCoV-2 (OIE, 2020). In April 2020, five tigers (Two Malayan and three Amur tigers) and three African lions that exhibited respiratory signs (dry cough and some wheezing) were tested positive in the Bronx Zoo in New York City, USA. The test results were confirmed by the National Veterinary Services Laboratory at Lowa. It is assumed that an asymptomatic zoo employee infected the animals (OIE, 2020). In may, 2021 Eight Asiatic lions (4 males and 4 females) at Nehru Zoological Park in Hyderabad tested positive for Covid-19 after wildlife veterinarians working in the park noticed coronavirus-like symptoms including loss of appetite, nasal discharge and coughing among the lions. Oropharyngeal swab samples of the lions were sent to The Centre for Cellular and Molecular Biology in Hyderabad. The CCMB scientists are still to do genome sequencing to figure out if this strain came from animals or human beings (Businesstoday, 2020).

There have been repeated assertions by WHO, CDC and several veterinary entities that companion animals were "unlikely" to get infected with SARS-CoV-2. But then pet dogs and cats tested positive in various countries. Although the same organizations had stated that pets would not become ill, the cat in Belgium presented with clinical signs. In addition to these animals, lions, tigers, ferrets and minks were also infected. In the situation reports of February 5 and 22 (World Health Organization, 2020), WHO states there is a need to "identify and reduce transmission from the animal source.' WHO in May 2021 reclassified a highly contagious triple mutant Covid variant identified in India during April 2021 as a "variant of concern"' indicating it to be a global health threat. Although it is still not certain that humans can transmit COVID19 to their pets or other animals, whether mutated SARS-CoV-2 can affect animals, it is recommended to follow some preventive measures and basic animal hygiene. There is no literature proving the transmission of the virus from the infected pets to their owners. However, social distancing needs to be maintained with animals as with humans. By doing so, we can reduce the human as well as zoonotic transmission of SARS-CoV-2. Furthermore, some experiment and studies and serosurveillance studies in different animal species should be continued to reach an effective conclusion and prevent further zoonotic events. Further, large scale screening of animals especially felines including pet cats will throw some light to the role of pet animals in maintenance and transmission of the disease.

\section{References}

Abdel-Moneim, A. S., and Abdelwhab, E. M. 2020. Evidence for SARS-CoV-2 infection of animal hosts. Pathogens. 9(7): 529.

Andersen, K., Rambaut, A., Lipkin, W. I., Holmes, E. C., and Garry, R. F. 2020. The Proximal Origin of SARS-CoV-2. Nat. Med. 26: 450-452.

Du, B., Qiu, H. B., Zhan, X., Wang, Y. S., Kang, H. Y. J., Li, X. Y., Wang, F., Sun, B., and Tong, Z. H. 2020. Pharmacotherapeutics for the new coronavirus pneumonia. Chinese Journal of Tuberculosis and Respiratory diseases 43 (3): 173-176.

Fan, Y., Zhao, K., Shi, Z. L., and Zhou P. 2019. Bat Coronaviruses in China. Viruses. 11(3):210. 
Gorbalenya, A. E., Baker, S. C., Baric, R. S., de Groot, R. J., Drosten, C., Gulyaeva, A. A., Haagmans, B. L., Lauber, C., Leontovich, A. M., Neuman, B. W., et al., 2020. The species severe acute respiratory syndrome-related coronavirus: classifying 2019-nCoV and naming It SARS-CoV-2. Nat Microbiol. 5(4):536-544.

Gralinski, L. E., and Menachery, V. D. 2020. Return of the coronavirus: 2019-nCoV. Viruses. 12(2):135.

Ji, W., Wang, W., Zhao, X., Zai, J., and Li, X. 2020. Cross-species transmission of the newly identified coronavirus 2019nCoV. J Med Virol. 92(4) :433-40.

Ji, W., Wang, W., Zhao, X., Zai, J., and Li, X. 2020. Homologous recombination within the spike glycoprotein of the newly identified coronavirus may boost cross-species transmission from snake to human. J Med Virol. 92(4): DOI:10.1002/jmv.25682.

Lam, T. T. Y., Shum, M. H. H., Zhu, H. C., Tong, Y. G., Ni, X. B., Liao, Y. S., Wei, W., Cheung, W. Y., Li, W. J., Li, L. F., Leung, G. M., Holmes, E. C., $\mathrm{Hu}$, Y. L., and Guan, Y. 2020. Identifying SARS-CoV-2 related coronaviruses in Malayan pangolins. Nature. 583: 282-285.

Li, H, Liu, S. M., Yu, X. H., Tang, S. L., and Tang, C. K. 2020. Coronavirus disease 2019 (COVID-19): current status and future perspective. Int $\mathrm{J}$ Antimicrob Agents. 55(5): 105951. doi: 10.1016/j.ijantimicag.2020.105951.

Li, X., Zai, J., Zhao, Q., Nie, Q., Li, Y., Foley, B. T., et al., 2020. Evolutionary history, potential intermediate animal host, and cross-species analyses of SARS-CoV-2. J Med Virol. 92(6):602611.

Lu, R., Zhao, X., Li, J., Niu, P., Yang, B., Wu, $\mathrm{H}$. et al., 2020. Genomic characterisation and epidemiology of
2019 novel coronavirus: implications for virus origins and receptor binding. Lancet. 395(10224): 565-574.

Mallapaty, S. 2020. Coronavirus can infect cats - dogs, not so much. Nature. doi: 10.1038/d41586-020-00984-8.

OIE. 2020. Events in animals. Spain. https ://www.oie.int/en/scien tific -exper tise/ speci fic-infor matio n-and-recom menda tions /quest ions-and-answe rson- 2019n ovel-coron aviru s/event sin-animals/.

OIE. 2020. SARS-CoV-2/COVID-19, United States of America. https ://www. oie.int/wahis 2/publi c/wahid.php/Revie wrepo rt/Revie w?page_refer $=\mathrm{MapFu}$ llEve ntRep ort\&repor tid $=33885$.

OIE. 2020. SARS-CoV-2/COVID-19, United States of America. https ://www.oie. int/wahis 2/publi c/wahid.php/Revie wreport/Revie w?repor tid=34054.

Oreshkova, N., Molenaar, R. J., Vreman, S., Harders, F., Munnink, B. B. O., Hakze-van der Honing, R.W., et al., 2020. SARS-CoV-2 infection in farmed minks, the Netherlands, April and May 2020. Eurosurveillance. 25(23):2001005.

Phadke, M., and Saunik, S. 2020. COVID-19 treatment by repurposing drugs until the vaccine is in sight. Drug Dev Res. 81(5): 541-543.

Richard, M., Kok, A., de Meulder, D., Bestebroer, T. M., Lamers, M. M., Okba, N. M., et al., 2020. SARS-CoV2 is transmitted via contact and via the air between ferrets. Nature Communications. 11:3496.

Rothan, H. A., and Byrareddy, S. N. 2020. The epidemiology and pathogenesis of coronavirus disease (COVID-19) outbreak. J Autoimmunity. 109:102433.doi: 10.1016/j.jaut.2020.102433.

Schlottau, K., Rissmann, M., Graaf, A., 
Schön, J., Sehl, J., Wylezich, C., et al.,2020. SARSCoV- 2 in fruit bats, ferrets, pigs, and chickens: an experimental transmission study. Lancet Microbe. 1(5):e218-e225225. doi: 10.1016/S2666-5247(20)30089-6.

Shi, J., Wen, Z., Zhong, G., Yang, H., et al., 2020. Susceptibility of ferrets, cats, dogs, and different domestic animals to SARS-corona virus-2. Science. 368: 1016-1020.

Sit, T. H. C., et al., 2020. Infection of dogs with SARS-CoV-2. Nature. 586: 776778.

Syed, A. 2020. Coronavirus: a mini-review. Int J Curr Res Med Sci. 6(1):8-10.

Temmam, S., Barbarino, A., Maso, D., Behillil, S., Enouf, V., Huon, C. et al., 2020. Absence of SARS-CoV-2 infection in cats and dogs in close contact with a cluster of COVID-19 patients in a veterinary campus. One Health. 10: 100164.doi: 10.1016/j.onehlt.2020.100164.

Totura, A. L., and Bavari, S. 2019. Broad- spectrum coronavirus antiviral drug discovery. Expert Opin Drug Discov. 14(4):397-412.

Tyrrell, D. A., and Fielder, M. 2002. Cold Wars: The Fight Against the Common Cold. Oxford University Press. p. 96. ISBN 978-0-19-263285-2.

World Health Organization. 2020. Coronavirus disease 2019 (COVID19) situation report -33 . Available at https://www.who.int/docs/defaultsource/coronaviruse/situationreports/202002.

Xiao, K. P., Zhai, J. Q., Feng, Y. Y., Zhou, N., Zhang, X., Zou, J. J., et al., 2020. Isolation and characterization of. 2019 -nCoV-like coronavirus from Malayan Pangolins. Nature. 583: 286-289.

Zhang, Y. Z. and Holmes, E. C. 2020. A genomic perspective on the origin and emergence of SARS-CoV-2. Cell. 181(2):223-227.

Zheng, J. 2020. SARS-CoV-2: an emerging coronavirus that causes a global threat. Int J Biol Sci. 16(10): 1678-1685.

\section{How to cite this article:}

Indhu Prathibha, A., V. Bhanu Rekha and Ajay Kumar, V. J. 2021. Covid-19 and Animals: A Review. Int.J.Curr.Microbiol.App.Sci. 10(06): 167-174. doi: https://doi.org/10.20546/ijcmas.2021.1006.018 